\title{
Current State of Off-Site Manufacturing in Australian and Chinese Residential Construction
}

\author{
Malik M. A. Khalfan and Tayyab Maqsood \\ School of Property, Construction and Project Management, RMIT University, Melbourne, VIC 3000, Australia
}

Correspondence should be addressed to Malik M. A. Khalfan; malik.khalfan@rmit.edu.au

Received 6 June 2014; Accepted 19 September 2014; Published 25 September 2014

Academic Editor: F. Pacheco-Torgal

Copyright (C) 2014 M. M. A. Khalfan and T. Maqsood. This is an open access article distributed under the Creative Commons Attribution License, which permits unrestricted use, distribution, and reproduction in any medium, provided the original work is properly cited.

\begin{abstract}
Many techniques have been implemented to make construction industry more productive. The key focus is on reduction of total duration, reduction in construction cost, improvements in the quality, achieving more sustainable development, and safer construction sites. One of the techniques, which is emerging in the last two decades, is the use of off-site manufacturing (OSM) within the construction industry. Several research projects and industry initiatives have reported the benefits and challenges of implementation of OSM. The focus of this paper is Australian and Chinese residential construction industry and the uptake of the OSM concepts. The paper presents a brief review of the current state of OSM in the last five to seven years with the context of the above-mentioned two countries. The paper concludes that the construction industry, both in Australia and China, needs to start walking the talk with regard to OSM adoption. The paper also highlights some of the research gaps in the OSM area, especially within the housing and residential sector.
\end{abstract}

\section{Introduction}

This paper provides a review of academic work done in the area of off-site manufacturing (OSM) in the last 5-7 years in Australia and China. The reasons to focus on Australia and China are ongoing economic activities between these countries; current initiatives to import construction materials from China to Australia; increasing interest of Australian researchers in understating the uptake of OSM in China so that lessons could be learnt; and knowledge transfer between two countries within the area of new methods of construction including OSM.

A brief update has been provided on the activities in different parts of the world in this paper, followed by academic work done in Australia and China. Research gaps are also highlighted. The second half of this section focuses on the industry uptake of OSM with examples from Australian residential housing construction sector. The paper also presents the envisaged benefits as well as encountered challenges faced by different researchers when studying the implementation of OSM in different parts of the world.

\section{OSM: An Overview}

The purpose of modern methods of construction including prefabrication, off-site construction, or manufacturing is to move some of the activities from on-site construction to offsite into a controlled manufacturing environment. Gibb [1] traces back the history of manufactured construction as far back as 1851, but Arif [2] actually goes one step further and argues that the use of big boulders instead of smaller bricks in pyramids is no different than using prefabricated wall panels [3].

Off-site manufacturing (OSM) is a construction technique in which prefabricated and standardised components/modules are manufactured in a controlled factory environment (either on- or off-site), transported, erected, and assembled into the on-site structure. OSM requires rethinking about the entire project development process, in order to take full advantage of both on- and off-site activities. Construction industry players in many countries started to think about innovative ways of construction by integrating the off-site production with the on-site activities. In the UK, 
off-site manufacturing has seen huge momentum since the Egan report [4]; the size of off-site construction industry in the UK grew from $£ 2.2$ billion in 2004 to $£ 6$ billion in $2006[5,6]$. The Construction Industry Master Plan 20062015 in Malaysia has given significant importance to the offsite manufacturing. The term used is Industrialised Building System (IBS) and is defined as a construction technique in which components are manufactured in a controlled environment (on- or off-site), transported, positioned, and assembled into an on-site structure with minimal additional site works [7]. Likewise, the Australian construction industry has identified off-site manufacturing as a key vision for improving the industry in the coming decade $[8,9]$. In China, in order to increase the uptake of sustainable practices, off-site manufacturing has been repeatedly promoted as a potentially viable alternative [10].

Arif and Egbu [3] identified several factors that have impacted the construction industry in the last decade resulting into moving from traditional construction methods to modern methods of construction. These include the emergence of knowledge-based environment; rapid change in information technology; and changing marketplace and competition [11]. More specific drivers for the use of OSM are considered to be addressing traditional construction skill shortages, ensuring time and cost certainty and achieving high quality $[3,7,12]$.

Pan et al. [12] also identified significant barriers against the use of OSM through their survey of the U.K.'s leading house builders. They concluded that OSM was perceived to be requiring higher capital cost and complex interfacing between off-site and on-site components and systems. The nature of design development process, the risk-averse culture, fragmented industry structure, manufacturing capacity, the local government planning system and concerns of mortgage lenders, and insurers with nontraditional buildings were also considered hindering the effective uptake of OSM within the UK housing industry.

Some of the key benefits of using OSM approach include [3] better quality control; effective resource utilisation; improved waste reduction; improved health and safety; tighter integration of the supply chain partners; greater economies of scale. According to Pan and Goodier [13], the UK construction industry has seen the benefits of OSM adoption that include reductions in time, defects, health and safety risks, environmental effects, and whole-life cost and consequently has seen increase in sustainability, productivity, whole-life performance, and profitability.

\section{Off-Site Manufacturing (OSM) in Chinese Residential Sector}

The construction sector in China accounts for about 6.5 per cent of the total GDP, employing about 42 million people in 71,863 construction-related enterprises [10,14]. Along with the growth of the construction sector, there have been reforms and arrival of international construction companies in China, resulting into uptake of new construction techniques such as OSM into the Chinese construction sector.
Jaillon et al. [15] have identified that, for Hong Kong, the waste reduction benefit from adopting OSM is $52 \%$, which is a significant saving on the island struggling to find landfill sites. Tam et al. [16] concluded that although there are many hindrances to OSM in Hong Kong, skilled supervision can lead to achieving better environment and quality of the final product. Jaillon and Poon [17] and Jaillon et al. [15] highlighted some of the barriers to the implementation of OSM in Hong Kong that include conflict with traditional design and construction processes and practices; lack of incentives for adopting OSM; lack of support from client due to overall high cost; lack of skilled labour; and so forth [3].

Arif and Egbu [3] also identified the challenge related to cultural change within the construction industry where onsite construction has been practiced for many decades. They suggested that, through education and motivation, one would be able to bring this change within the industry to move to offsite construction. This also would require strong leadership and government support in various countries.

Zhai et al. [10] conducted their research by identifying six factors hindering the adoption of the OSM within the Chinese context including "constructability implementation," "social climate and attitudes," "architectural performance," "costing," "supply chain," and "preparatory stage." Despite all these barriers, Hong [18] points out that OSM have increasingly become a major alternative construction method in China. One of the major reasons for OSM uptake is to meet the demand for increased quantity and quality housing stock combined with achieving environmental sustainability [10].

Another recent study by Zhang and Skitmore [19] focuses specially on adoption of OSM in the residential housing sector. The research presents lists of the benefits and hindrances of OSM implementation in China. They concluded after the analysis of the survey and case studies that there are two major hurdles for the adoption of OSM in China; OSM is not a cost effective construction method in comparison to the traditional construction method; and there are insufficient manufacturers of prefabricated construction components for OSM to be viable on any scale throughout the country. They feared that insensitive design and planning decisions in order to exploit the potential of OSM to achieve cheapest cost could put off the prospective buyers and residents of the housing stock.

\section{Off-Site Manufacturing (OSM) in Australian Residential Sector}

"Australia's building and construction industry contributes over $\$ 200$ billion to the economy and represents $7.5 \%$ of GDP. It is estimated that even a small productivity increase of $0.3 \%$ would result in a national improvement in GDP of $\$ 6.6$ billion - this forecast is double that of any other industry." [20, pp.1]

Most of the above mentioned construction activities are done using traditional methods. Blismas [21] reported a major study done in Australia with cases to identify the current uptake and future direction of OSM almost seven years ago. Kanjanabootra et al. [22] reported recent OSM 
research in the area of nonresidential sector but not much research was done in the residential sector in the last few years. The uptake of OSM in housing sector is very slow and there is no real prospect of systematic movement from onsite to off-site production [23]. The major reasons include the lack of capacity to set up the factories necessary for large-scale off-site manufacture of building components; traditional approach to house design; and lack of understanding of basic characteristics of mass production. Dalton et al. [23] concluded that

"Any move towards off-site manufacturing of the type envisaged by Hampson and Brandon [9] in housing production would require the development of a very different paradigm for house design, and/or an approach to a "bespoke" form of offsite manufacturing. (pp.38)"

Boyd et al. [24] reported in detail the major drivers and barriers within the Australian context using literature search. The case study presented by the authors in their paper shows the current uptake of the OSM in low rise apartment building construction using an innovative technology called the unitized building (UB) approach, but that involves only a limited number of players.

A recent report shows that the neighbouring country, New Zealand (NZ), has a fast uptake of the OSM techniques, as highlighted by PrefabNZ (http://www.prefabnz.com/). This BRANZ report [25], commissioned by one of the partners of PrefabNZ, highlights the benefits, drivers, and barriers of using OSM with many examples of OSM from around the country, both residential and commercial. The report summaries that OSM provides more security in economic outcomes and better environmental outcomes compared to on-site construction in NZ. Improved economic outcome includes reduced initial capital cost, shorter construction time periods, and reduced site access requirements. Enhancing environmental sustainability includes reduced waste, transport needs, and greenhouse gas emission.

\section{Uptake of Off-Site in Australian Residential Sector}

So what is the future of OSM in Australia? Chandler [20] recently wrote a discussion paper where he talked about the way forward. The discussion paper outlines a framework for an Australian Construction Industry Strategy, highlighting multiple factors including adoption of OSM. The paper foresees the increase of utilisation of OSM in the order of 15$20 \%$ of the total construction turnover by 2023 . The author argues that the underperforming construction industry in Australia could take advantage of emerging ICT technology and building technology, including adaption of Building Information Modelling (BIM) and OSM. But the challenges are many including the lack of skilled Australian supply chain partners to take OSM on board for their projects; lack of scale especially in residential sector; lack of support from the government. The paper presents suggestive initiatives for OSM adoption based on the best practices in different parts of the world. The discussion paper echoes some of the key aspects identified to improve productivity within the Australian construction industry by the Built Environment Industry Innovation Council in their final report to the minister [26]. One of the recommendations in the report was to maximize the time, cost, and quality efficiencies of OSM and minimize exposure to on-site variables.

Formation of networks such as PrefabAUS in late 2013, and launch of Buildoffsite from UK to Australia in May 2014, the Australian industry players are now getting excited by the marvels of OSM and its related activities. PrebabNZ is very well established body in NZ, advocating the adoption of OSM during their seminars by presenting the case of reduced cost and waste through OSM.

According to Chandler [20], the status quo within construction industry is not sustainable. In order to drive the costs down by at least 20 per cent and durations down by at least 50 per cent in the medium term with significant improvements in construction quality and on-site safety, the Australian construction industry needs to go off-site. The same is true for Chinese construction industry where more emphasis is on improving sustainability and reduction of onsite logistics.

In the recent past, Melbourne has seen a few examples of residential apartments being constructed using off-site manufacturing technologies. Unitised Building (UB) system is one of these technologies used in the construction of apartment buildings both within the $\mathrm{CBD}$ and in other suburbs. According to UB website, "[UB is] an innovative... construction technology that enables a wide range of property developments to be delivered in a significantly faster, more economical and more sustainable manner." (http://www .unitisedbuilding.com/).

The system was adopted for a multipurpose development including both retail and residential apartment block in Melbourne CBD; the project is called Little Hero in Russell Street. Both the designer and constructor employed the UB system for the construction of the project, utilising a parallel on- and off-site construction program which reduced construction time by more than 6 months compared with a conventional build. As a result the 8 -storey building was erected just in 4 weeks. The pods constructed in the UB factory were initially manufactured using a linear assembly line process and remained in sequence in terms of final delivery and installation. Delivery of the pods was done just in time to the site, which reduced lead times. The current production cycle is 20 modules per week, with floor space for 120 modules [24].

\section{Research Gaps}

Some of the gaps in the research are described below which were highlighted during the OSM literature review done for Australia and China. The challenge of changing the perception of the end users about the OSM is clearly the biggest one, especially in the Chinese context, which is partly related to the social and cultural influences. The lack of leadership (either through an established client or constructor) within the industry to change this perception makes the situation 
even worse. In addition to that the players within the industry are happy with the status quo. The harder challenge will be breaking through to drive the industry-wide changes in both the countries.

Although the skill aspect was talked by Daly [27] in his report, but there is no evidence of any actions within the Australian industry. Within the Chinese context, the up skilling of the workers would also be a huge challenge because of the nature of labour market in the urban cities. The lack of sufficient number of manufacturers of prefabricated construction components for OSM is also one of the hindering factors when it comes to plan and structure training programs for this new emerging technology.

A good number of studies have been conducted in the area of on- and off-site logistics in other parts of the world, but there is little or no research done in this area within both Australian and Chinese contexts. On the other hand, the issue related to the readiness of supply chain to embrace the OSM also remains untouched in the above-mentioned contexts. The conflict arises with adoption of OSM with traditional design and construction processes and practices could be resolved through restricting and integrating the supply chain from the outset of a project. Such integration would help in efficient design management considering both the constructability and sustainability aspects of the entire project development.

Another emerging area is use of Building Information Modelling (BIM) for the OSM. BIM has been researched for its adoption for traditional projects [28]; not much is done to utilise BIM for OSM projects. Adoption of BIM to OSM projects could result into significant insight regarding the management of interfaces specially between off-site manufacturing and transportation and on-site installation.

In addition to this, there are claims about achieving sustainability as outcomes through OSM but there are not much academic studies in this area to proof such claims through evidence, both in Chinese and Australian context. Although the data could be accessed from some of the ongoing projects, it requires thorough research investigation to interpret such data because the perception and measurement of sustainability could be varied in different contexts.

Last but not least there is lack of incentives for adopting OSM for both clients and constructors. The option becomes further unattractive because it requires higher capital cost, therefore lack of support especially from client towards adoption of OSM on their projects in comparison to the traditional construction method.

Despite the huge amount of information available, there is also a big challenge of transferring the knowledge from academia to industry, as well as from industry practices back to academia. This knowledge transfer is very important in order to achieve any collaborative progress resulting into adoption in the area of OSM in the coming years.

\section{Conclusion}

The above discussion concludes that the construction industry both in Australia and China needs to start walking the talk with regards to OSM. If the main issue is affordability, then the trade-offs need to be highlighted such as reduction in time and increase in quality. But this is not enough; one needs to take into account of the skills required in introducing OSM and the complexities of interface between design, manufacture, and on-site installation.

Visionary leadership is also required to see the current and future problems within the industry, challenge the status quo, and plan towards achieving integration of available technology, innovation, and project development process. A whole new set of business processes is required through reengineering of the entire current work practices and analysis of existing workflow. It also requires the entrepreneur skills at different levels of leadership to sell the idea of OSM and achieve economies of scales for the sustenance of the emerging manufacturing facilities. A lot of academic and industry based works need to be done in the area of OSM and this requires the full collaboration between researchers and practitioners.

\section{Conflict of Interests}

The authors declare that there is no conflict of interests regarding the publication of this paper.

\section{References}

[1] A. Gibb, "Standardization and pre-assembly- distinguishing myth from reality using case study research," Construction Management and Economics, vol. 19, no. 3, pp. 307-315, 2001.

[2] M. Arif, "Editorial-special issue on offsite manufacturing," Construction Innovation, vol. 9, no. 1, pp. 5-6, 2009.

[3] M. Arif and C. Egbu, "Making a case for offsite construction in China," Engineering, Construction and Architectural Management, vol. 17, no. 6, pp. 536-548, 2010.

[4] J. Egan, "Rethinking construction," The Egan Report, Department of the Environment, Transport and the Regions, London, UK, 1998.

[5] C. Goodier and A. Gibb, "Future opportunities for offsite in the UK," Construction Management and Economics, vol. 25, no. 6, pp. 585-595, 2007.

[6] A. Gibb, Offsite Construction Industry Survey-2006, Build Offsite, London, UK, 2007.

[7] K. A. M. Kamar, Z. Abd. Hamid, M. K. Ghani, C. Egbu, and M. Arif, "Collaboration initiative on green construction and sustainability through Industrialized Buildings Systems (IBS) in the Malaysian construction industry," International Journal of Sustainable Construction Engineering and Technology, vol. 1, no. $1,2010$.

[8] N. Blismas and R. Wakefield, "Drivers, constraints and the future of offsite manufacture in Australia," Construction Innovation, vol. 9, no. 1, pp. 72-83, 2009.

[9] K. Hampson and P. Brandon, Construction 2020: A Vision for Australia's Property and Construction Industry, Cooperative Research Centre for Construction Innovation, Brisbane, Australia, 2004.

[10] X. Zhai, R. Reed, and A. Mills, "Factors impeding the offsite production of housing construction in China: an investigation of current practice," Construction Management and Economics, vol. 32, no. 1-2, pp. 40-52, 2014. 
[11] P. S. Chinowsky and J. E. Meredith, "Strategic management in construction," Journal of Construction Engineering and Management, vol. 126, no. 1, pp. 1-9, 2000.

[12] W. Pan, A. F. Gibb, and A. R. J. Dainty, "Perspective of UK housebuilders on the use of offsite modern methods of construction," Construction Management and Economics, vol. 25, no. 2, pp. 183-194, 2007.

[13] W. Pan and C. Goodier, "House-building business models and off-site construction take-up," Journal of Architectural Engineering, vol. 18, no. 2, pp. 84-93, 2012.

[14] C. Egbu, "Technology and knowledge transfer in China," Journal of Technology Management in China, vol. 1, no. 3, pp. 304321, 2006.

[15] L. Jaillon, C. S. Poon, and Y. H. Chiang, "Quantifying the waste reduction potential of using prefabrication in building construction in Hong Kong," Waste Management, vol. 29, no. 1, pp. 309-320, 2009.

[16] V. Tam, C. Tam, S. Zeng, and W. Ng, “Towards adoption of prefabrication in construction," Building and Environment, vol. 42, no. 10, pp. 3642-3654, 2007.

[17] L. Jaillon and C. S. Poon, "Sustainable construction aspects of using prefabrication in dense urban environment: a Hong Kong case study," Construction Management and Economics, vol. 26, no. 9, pp. 953-966, 2008.

[18] P. Hong, Application of industrialized housing system in major cities in China-a case study of Chongquing [Ph.D. thesis], Department of Building and Real Estate, The Hong Kong Polytechnic University, Hong Kong, 2007.

[19] X. Zhang and M. Skitmore, "Industrialized housing in China: a coin with two sides," International Journal of Strategic Property Management, vol. 16, no. 2, pp. 143-157, 2012.

[20] D. Chandler, "A case for an Australian Construction Strategy," Commonwealth Government Productivity and Industry Discussion Paper, 2014, http://constructionedge.com.au/?p=1290.

[21] N. G. Blismas, Off-Site Manufacture in Australia: Current State and Future Directions, Cooperative Research Centre for Construction Innovation, Brisbane, Australia, 2007.

[22] S. Kanjanabootra, M. T. Wynn, C. Ouyang, R. Kenley, and T. Harfield, "Re-use of domain knowledge to provide confidence for adoption of off-site manufacturing for construction in Australia," in Proceedings of the Construction, Building and Real Estate Conference, D. Kashiwagi and K. Sullivan, Eds., pp. 12701277, Las Vegas, Nev, USA, 2012.

[23] T. Dalton, J. Hurley, E. Gharaie, R. Wakefield, and R. Horne, "Australian suburban house building: industry organisation, practices and constraints," AHURI Final Report 213, 2013.

[24] N. Boyd, M. M. A. Khalfan, and T. Maqsood, "Off-site construction of apartment buildings," Journal of Architectural Engineering, vol. 19, no. 1, pp. 51-57, 2013.

[25] BRANZ, "Prefabrication impacts in the New Zealand construction industry," BRANZ Report, BRANZ, 2013.

[26] BEIIC, "Built environment industry innovation council," Final Report to Government DIISRTE 12/230, 2012.

[27] G. Daly, "Prefabricated housing in Australia. Skill deficiencies and workplace practice," International Specialised Skills Institute Report, 2009.

[28] S. Azhar, M. Khalfan, and T. Maqsood, "Building information modeling (BIM): now and beyond," Australasian Journal of Construction Economics and Building, vol. 12, no. 4, pp. 15-28, 2012. 

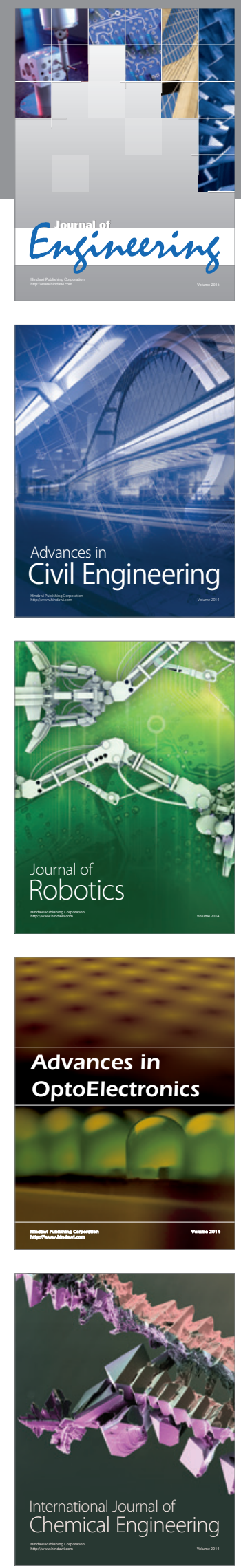

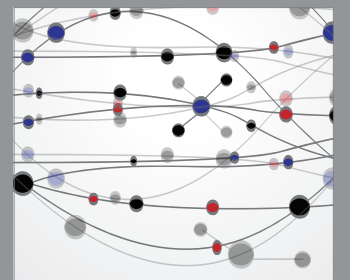

The Scientific World Journal
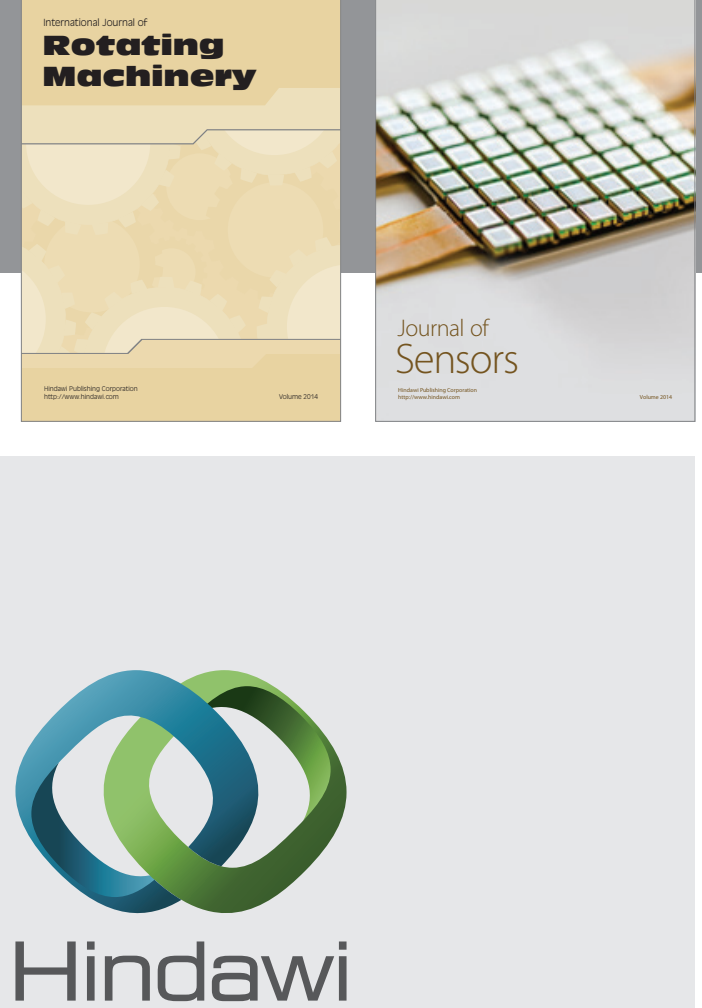

Submit your manuscripts at http://www.hindawi.com
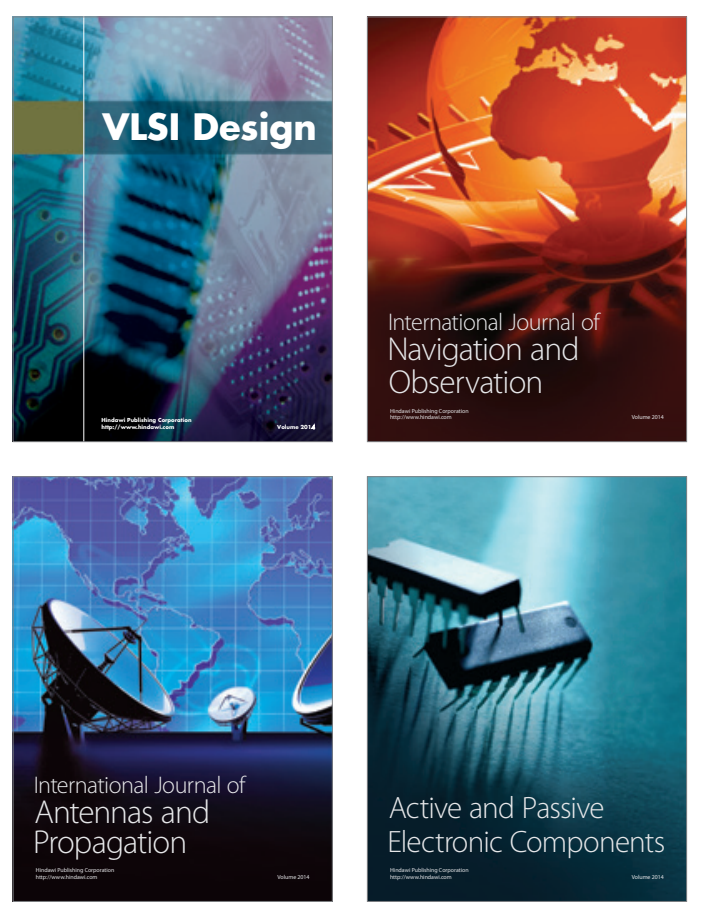
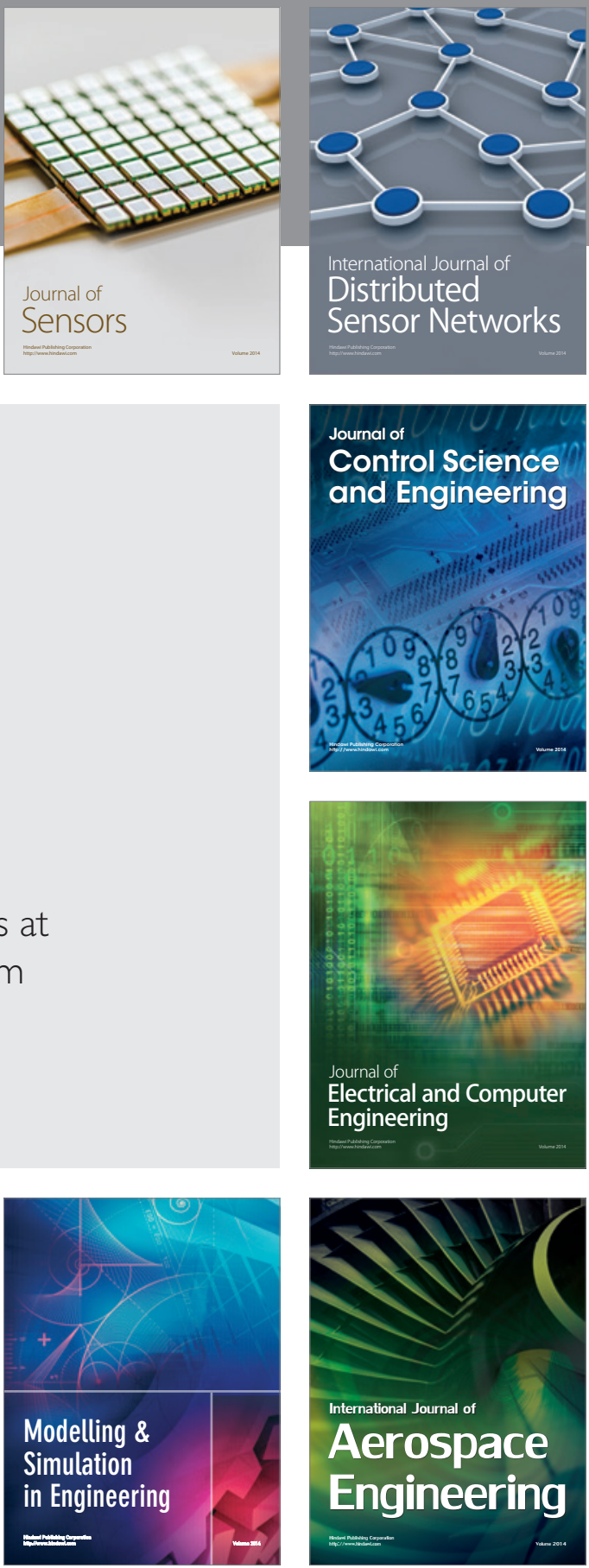

Journal of

Control Science

and Engineering
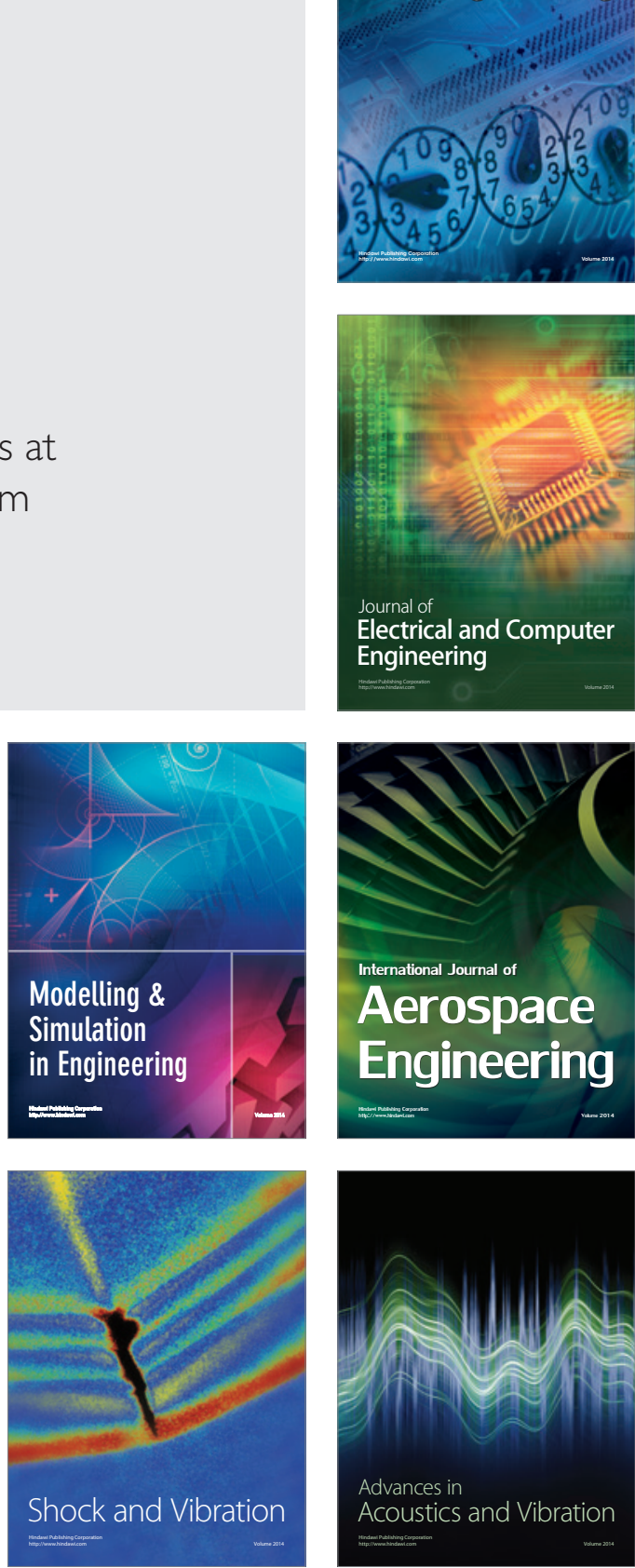